\title{
MODEL KEBUTUHAN RUANG PARKIR PADA PASAR MELATI MEDAN
}

\section{Orlando Ricky Daniel, Ahmad Perwira Mulia, Ridwan Anas}

Universitas Sumatera Utara, Indonesia

Email: orlandoricky66@yahoo.com, a.perwira.mulia@gmail.com, Ridwan.anas@usu.ac.id

\begin{tabular}{l}
\hline INFO ARTIKEL \\
\hline Diterima \\
25 Desember 2021 \\
Direvisi \\
05 Januari 2022 \\
Disetujui \\
15 Januari 2022 \\
\hline
\end{tabular}

Kata Kunci: parkir; lalu lintas; regresi linier

\section{ABSTRAK}

Parkir merupakan suatu kebutuhan bagi pemilik kendaraan. Biasanya pemilik kendaraan ini menginginkan kendaraannya parkir di tempat yang mudah dicapai. Dalam hal ini tempat yang mudah dicapai tersebut adalah pinggir jalan (on street parking). Penyediaan tempat-tempat parkir di pinggir jalan pada lokasi jalan tertentu mengakibatkan terhambatnya arus lalu lintas dan penggunaan jalan menjadi tidak efektif. Untuk itu sangat diperlukan pemodelan ruang parkir agar mengurangi dampak kemacetan lalu lintas seperti halnya di sekitar Pasar Melati Medan. Adapun tujuan pemodelan ruang parkir ini ialah untuk mengetahui jumlah luasan parkir yang dibutuhkan serta tarikan pergerakan orang dari rumah ke pasar Melati. Pemodelan kebutuhan parkir ini dihitung dengan jumlah kendaraan yang parkir seperti Mobil dan Sepeda Motor. Adapun yang dihitung ialah Akumulasi Parkir, Volume Parkir, Turn Over Parkir, Kebutuhan Ruang Parkir (SRP). Konsep yang digunakan untuk mengetahui model kebutuhan ruang parkir di Pasar Melati Medan dengan Metode Analisis Regresi Linier Berganda dengan menentukan variabel tetap dan variabel bebas yang berpengaruh terhadap jumlah kendaraan parkir dengan Analisis Regresi Linier. Hasil penelitian untuk pemodelan mobil yaitu: Ymobil Kiri $=-56,161-0,132 \mathrm{X} 4+$ 1,182 X8 dengan $\mathrm{R} 2=0,849$, Ymobil Kanan $=123,014-$ $0,014 \mathrm{X} 1+0,395 \mathrm{X} 8$ dengan $\mathrm{R} 2=0,978$. Untuk pemodelan motor yaitu: Ymotor Kiri $=24,542-0,443 \mathrm{X} 7+0,863 \mathrm{X} 8$ dengan R2 $=0,999$, Ymotor Kanan $=-47,194-0,004 \mathrm{X} 1+$ 1,162 X8 dengan $\mathrm{R} 2=0,883$ dengan luas parkir $2.466 \mathrm{~m} 2$.

\section{ABSTRACT}

Parking is a necessity for vehicle owners. Usually the owner of this vehicle wants his vehicle to be parked in a place that is easily accessible. In this case, the easily accessible place is the roadside (on street parking). The provision of parking lots on the roadside at certain road locations results in obstruction of traffic flow and ineffective use of roads. For this reason, it is very necessary to model parking spaces in order to reduce the impact of traffic jams as is the case around Pasar Melati

\section{How to cite:}

E-ISSN:

Published by:
Daniel, O. R., Ahmad Perwira Mulia, Ridwan Anas (2022) Model Kebutuhan Ruang Parkir Pada Pasar Melati Medan, Jurnal Syntax Admiration 3(1). https://doi.org/10.46799/jsa.v3i1.372 2722-5356

Ridwan Institute 
Medan. The purpose of this parking space modeling is to find out the amount of parking area needed and the attraction of the movement of people from the house to the Melati market. This parking demand modeling is calculated by the number of parked vehicles such as cars and motorbikes. As for what is calculated is accumulation parking, volume parking, turn over parking, parking space requirement (SRP). The concept used to determine the model of parking space requirements at the Pasar Melati Medan with the Multiple Linear Regression Analysis Method by determining the fixed and independent variables that affect the number of parking vehicles with Linear Regression Analysis. The results of the research for car modeling are: Ycar Left $=-56,161-0,132 X 4+1,182 X 8$ with $R 2=0,849$, Ycar Right $=123,014-0,014$ X1 + 0,395 X8 with $R 2=0,978$. For motorcycle modeling are: Ymotor Left $=$ Keywords: parking; $24,542-0,443 X 7+0,863$ X8 with $R 2=0,999$, Ymotor Right traffic; $\quad$ linear $=-47,194-0,004 X 1+1,162 \times 8$ with $R 2=0,883$ with $a$ regression parking area $2.466 \mathrm{~m} 2$.

\section{Pendahuluan}

Kota Medan adalah Ibu Kota dari Provinsi Sumatera Utara yang memiliki luas wilayah 265,1 km2 dengan jumlah penduduk 2.524.321 jiwa berdasarkan Badan Pusat Statistik 2020.

Seiring dengan perkembangan wilayah mengakibatkan adanya laju pertumbuhan penduduk dan pertumbuhan ekonomi yang setiap tahunnya semakin meningkat. Tingginya pertumbuhan ekonomi pada suatu kota akan memberi dampak yang sangat besar terhadap perkembangan suatu kota, terutama dampak terhadap sistem jaringan transportasi yang ada di kota, sehingga kebutuhan akan pergerakan lalu lintas akan menjadi semakin meningkat, yang pada gilirannya akan menimbulkan permasalahan perkotaan, khususnya transportasi (Tamin, 1997).

Sistem transportasi muncul akibat adanya pergerakan dan tarikan yang diakibatkan oleh perkembangan suatu kota. Pergerakan terjadi akibat pemenuhan kebutuhan manusia setiap hari yang harus dipenuhi. Dalam melakukan pergerakan membutuhkan suatu moda transportasi baik moda transportasi darat, laut, maupun udara. Moda transportasi dipilih berdasarkan pergerakan moda untuk jarak pendek maupun moda transportasi untuk jarak jauh (Warpani, 1990).

Moda transportasi dibagi menjadi 2 kelompok, pertama kendaraan pribadi seperti mobil, sepeda motor dan kedua kendaraan umum seperti bus, angkutan umum (Miro, 2005).

Pada pusat kota umumnya menggunakan kendaraan pribadi seperti mobil, sepeda motor sebagai moda transpotasi. Besarnya peningkatan kendaraan pribadi yang tidak diimbangi dengan peningkatan luas jalan, tentu akan mengakibatkan penumpukan kendaraan dan jalan akan menjadi jenuh. Sebagian badan jalan yang dialihfungsikan 
sebagai ruang parkir dapat menyebabkan terjadinya hambatan mobilitas arus lalu lintas hingga mengakibatkan kemacetan (Miro, 2005).

Sama seperti halnya dengan pasar melati medan, pasar ini cukup luas namun pihak pengelola pasar tidak menyediakan lahan parkir untuk para pengunjung, sehingga banyak kendaraan pribadi seperti mobil dan sepeda motor parkir di sepanjang badan jalan (on street parking) pada Jl. Flamboyan Raya Medan.

Hal ini dapat mengurangi kapasitas jalan sehingga menimbulkan kemacetan dikarenakan pengunjung pasar melati memarkirkan kendaraannya disepanjang badan jalan. Perilaku angkutan umum yang berhenti disembarang tempat juga mengakibatkan tundaan pada jam-jam sibuk pada pasar (Sudirahardjo, 2003).

Tujuan dari penelitian ini adalah menganalisis pemodelan kebutuhan ruang parkir dan kebutuhan luas area parkir untuk Pasar Melati Medan yang terletak di jalan kolektor primer. Hasil penelitian ini nantinya diharapkan dapat dijadikan pedoman dalam menentukan kebijakan-kebijakan yang berkaitan dengan kawasan tersebut dalam penentuan ruang parkir.

Analisis sebelumnya terkait perhitungan kebutuhan parkir juga telah dilakukan. (Lestari, 2018) melakukan evaluasi karakteristik dan kapasitas lahan parkir pada Rumah Sakit Daerah Idaman Banjarbaru dengan metode SRP. Metode SRP juga gunakan oleh (Wahida et al., 2018) dalam perencanaan kebutuhan ruang parkir di kawasan Taman Sari Kota Banda Aceh. Selain itu, (Zaenal, 2019) melakukan analisis karakteristik dan penentuan parkir di gedung Makassar New Mall menggunakan metode SRP.

Retyaningsih, 2018 melakukan pemodelan kebutuhan ruang parkir untuk toko Modern menggunakan metode regresi. (Atmaja et al., 2013) menggunakan metode regresi dalam perencanaan ulang desain parkir Pasar Bulu Kota Semarang dan (Putu Fany et al., 2014) juga menggunakan metode regresi dalam pemodelan kebutuhan parkir pada Pasar Tradisional di Kabupaten Badung. Selain itu pemodelan parkir pada gedung perbankan di kota Yogyakarta menggunakan metode regresi dilakukan oleh (Ansusanto, 2019), (Alvesa et al., 2019) juga melakukan analisis karakteristik dan model kebutuhan parkir di pasar tradisional di Kabupaten Tabanan. Sehingga dihasilkan model kebutuhan parkir untuk sepeda motor dan kendaraan ringan laiinnya. Metode regresi ini yang akan digunakan dalam penelitian ini untuk mendapatkan model kebutuhan parkir di pasar Melati Medan dengan beberapa variabel penentu. Metode ini tepat untuk digunakan mengingat jika terjadi perubahan kapasitas pada pasar karena menghasilkan koefisien yang diperlukan untuk masing-masing variable (Saragih, 2016).

\section{Metode Penelitian}

Pada penelitian ini, data yang digunakan didapatkan dari kegiatan survei. Data yang dihasilkan merupakan data primer dan data sekunder. Survei primer dilakukan dengan pengambilan data melalui survei tarikan di Jalan Flamboyan Raya. Survei dilakukan selama 8 hari dengan menghitung jumlah parkir mobil, jumlah parkir motor, jumlah pengunjung, jumlah kios, jumlah los, luas kios, luas los di pasar melati medan. Data sekunder merupakan data yang didapatkan berdasarkan hasil studi atau laporan- 
laporan kegiatan penelitian terdahulu, atau data-data yang didapatkan dari instansi terkait. Data sekunder adalah berupa peta lokasi penelitan, pengelompokan jalan dan penentuan sampel.

Metode analisis data yang digunakan dalam studi ini adalah cara analisis regresi linier berganda dengan menggunakan perangkat lunak Statistic Program for Special Science (SPSS). Dalam menganalisis data beberapa tahapan uji statistik harus dilakukan agar model bangkitan pergerakan yang dihasilkan nantinya dinyatakan, tahapan-tahapan itu adalah uji korelasi, pemilihan persamaan model yang optimum dan penarikan kesimpulan. Adapun lokasi survei yang dilakukan dapat dilihat pada gambar 1.

\section{Hasil dan Pembahasan}

\section{Analisis Parkir}

a. Akumulasi Parkir

Akumulasi dilakukan pada dara masuk keluar hari minggu 01 November 2020 - 08 November 2020 pada segmen 1 s/d segmen 5 pada pasar Melati Medan. Adapun contoh data tersebut disajikan pada Tabel dibawah.

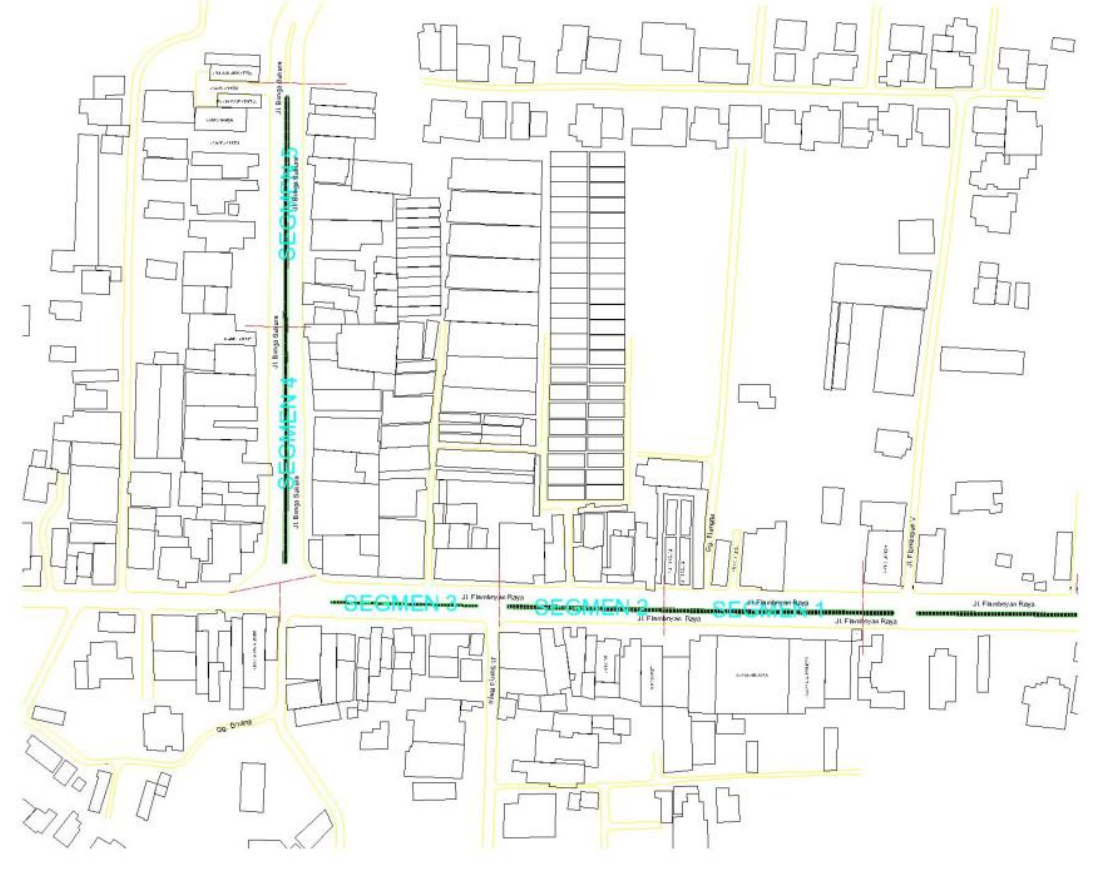

Gambar 1

Peta Garis Segmen 1 - Segmen 5

Pasar Melati 5 Medan 
Tabel 1

Akumulasi Parkir Mobil di Segmen 1 Kiri

\begin{tabular}{cccccc}
\hline WAKTU & $\begin{array}{c}\text { Kendaraan } \\
\text { Masuk } \\
\text { (Mobil) }\end{array}$ & $\begin{array}{c}\text { Kumulatif } \\
\text { Kendaraan } \\
\text { Masuk }\end{array}$ & $\begin{array}{c}\text { Kendaraan } \\
\text { Keluar } \\
\text { (Mobil) }\end{array}$ & $\begin{array}{c}\text { Kumulatif } \\
\text { Kendaraan } \\
\text { Keluar }\end{array}$ & $\begin{array}{c}\text { Akumulasi } \\
\text { (Mobil) }\end{array}$ \\
\hline $08.00-09.00$ & 63 & 63 & 28 & 28 & 35 \\
\hline $09.00-10.00$ & 36 & 99 & 38 & 66 & 33 \\
\hline $10.00-11.00$ & 53 & 152 & 36 & 102 & 50 \\
\hline $11.00-12.00$ & 33 & 185 & 44 & 146 & 39 \\
\hline $13.00-14.00$ & 81 & 266 & 30 & 176 & 90 \\
\hline $14.00-15.00$ & 51 & 317 & 40 & 216 & 101 \\
\hline $15.00-16.00$ & 53 & 370 & 53 & 269 & 101 \\
\hline $16.00-17.00$ & 42 & 412 & 47 & 316 & 96 \\
\hline $17.00-18.00$ & 38 & 450 & 70 & 386 & 64 \\
\hline $18.00-19.00$ & 5 & 455 & 16 & 402 & 53 \\
\hline
\end{tabular}

Tabel 2

Akumulasi Parkir Mobil di Segmen 1 Kanan

\begin{tabular}{cccccc}
\hline WAKTU & $\begin{array}{c}\text { Kendaraan } \\
\text { Masuk } \\
\text { (Mobil) }\end{array}$ & $\begin{array}{c}\text { Kumulatif } \\
\text { Kendaraan } \\
\text { Masuk }\end{array}$ & $\begin{array}{c}\text { Kendaraan } \\
\text { Keluar } \\
\text { Mobil) }\end{array}$ & $\begin{array}{c}\text { Kumulatif } \\
\text { Kendaraan } \\
\text { Keluar }\end{array}$ & $\begin{array}{c}\text { Akumulasi } \\
\text { (Mobil) }\end{array}$ \\
\hline $08.00-09.00$ & 73 & 73 & 23 & 23 & 50 \\
\hline $09.00-10.00$ & 50 & 123 & 32 & 55 & 68 \\
\hline $10.00-11.00$ & 54 & 177 & 47 & 102 & 75 \\
\hline $11.00-12.00$ & 37 & 214 & 48 & 150 & 64 \\
\hline $13.00-14.00$ & 94 & 308 & 24 & 174 & 134 \\
\hline $14.00-15.00$ & 82 & 390 & 34 & 208 & 182 \\
\hline $15.00-16.00$ & 62 & 452 & 38 & 246 & 206 \\
\hline $16.00-17.00$ & 31 & 483 & 54 & 300 & 183 \\
\hline $17.00-18.00$ & 28 & 511 & 117 & 417 & 94 \\
\hline $18.00-19.00$ & 0 & 511 & 22 & 439 & 72 \\
\hline
\end{tabular}

Tabel 3

Akumulasi Parkir Motor di Segmen 1 Kiri

\begin{tabular}{cccccc}
\hline WAKTU & $\begin{array}{c}\text { Kendaraan } \\
\text { Masuk } \\
\text { (Motor) }\end{array}$ & $\begin{array}{c}\text { Kumulatif } \\
\text { Kendaraan } \\
\text { Masuk }\end{array}$ & $\begin{array}{c}\text { Kendaraan } \\
\text { Keluar } \\
\text { (Motor) }\end{array}$ & $\begin{array}{c}\text { Kumulatif } \\
\text { Kendaraan } \\
\text { Keluar }\end{array}$ & $\begin{array}{c}\text { Akumulasi } \\
\text { (Motor) }\end{array}$ \\
\hline $08.00-09.00$ & 44 & 44 & 2 & 2 & 42 \\
\hline $09.00-10.00$ & 37 & 81 & 14 & 16 & 65 \\
\hline $10.00-11.00$ & 22 & 103 & 31 & 47 & 56 \\
\hline $11.00-12.00$ & 16 & 119 & 40 & 87 & 32 \\
\hline $13.00-14.00$ & 73 & 192 & 11 & 98 & 94 \\
\hline $14.00-15.00$ & 60 & 252 & 20 & 118 & 134 \\
\hline $15.00-16.00$ & 36 & 288 & 32 & 150 & 138 \\
\hline $16.00-17.00$ & 15 & 303 & 44 & 194 & 109 \\
\hline $17.00-18.00$ & 22 & 325 & 64 & 258 & 67 \\
\hline $18.00-19.00$ & 0 & 325 & 27 & 285 & 40 \\
\hline
\end{tabular}


Tabel 4

Akumulasi Parkir Motor di Segmen 1 Kanan

\begin{tabular}{cccccc}
\hline WAKTU & $\begin{array}{c}\text { Kendaraan } \\
\text { Masuk } \\
\text { (Motor) }\end{array}$ & $\begin{array}{c}\text { Kumulatif } \\
\text { Kendaraan } \\
\text { Masuk }\end{array}$ & $\begin{array}{c}\text { Kendaraan } \\
\text { Keluar } \\
\text { (Motor) }\end{array}$ & $\begin{array}{c}\text { Kumulatif } \\
\text { Kendaraan } \\
\text { Keluar }\end{array}$ & $\begin{array}{c}\text { Akumulasi } \\
\text { (Motor) }\end{array}$ \\
\hline $08.00-09.00$ & 56 & 56 & 8 & 8 & 48 \\
\hline $09.00-10.00$ & 43 & 99 & 13 & 21 & 78 \\
\hline $10.00-11.00$ & 22 & 121 & 28 & 49 & 72 \\
\hline $11.00-12.00$ & 11 & 132 & 51 & 100 & 32 \\
\hline $13.00-14.00$ & 89 & 221 & 11 & 111 & 110 \\
\hline $14.00-15.00$ & 79 & 300 & 21 & 132 & 168 \\
\hline $15.00-16.00$ & 47 & 347 & 38 & 170 & 177 \\
\hline $16.00-17.00$ & 13 & 360 & 57 & 227 & 133 \\
\hline $17.00-18.00$ & 20 & 380 & 96 & 323 & 57 \\
\hline $18.00-19.00$ & 0 & 380 & 21 & 344 & 36 \\
\hline
\end{tabular}

Berdasarkan akumulasi data yang telah dilakukan, akumulasi parkir terbesar pada segmen 1 untuk mobil dan motor ialah 206 (mobil) jam 15.00 - 16.00 dan 177 (motor) jam 15.00 - 16.00. Untuk akumulasi parkir terbesar pada segmen 2 untuk mobil dan motor ialah 95 (mobil) jam 14.00 - 15.00 dan 395 (motor) jam 13.00 - 14.00. Untuk akumulasi parkir terbesar pada segmen 3 untuk mobil dan motor ialah 61 (mobil) jam 13.00 - 14.00 dan 1115 (motor) jam 15.00 - 16.00. Untuk akumulasi parkir terbesar pada segmen 4 untuk mobil dan motor ialah 76 (mobil) jam 15.00 - 16.00 dan 731 (motor) jam 15.00 - 16.00. Untuk akumulasi parkir terbesar pada segmen 5 untuk mobil dan motor ialah 247 (mobil) jam 15.00 - 16.00 dan 1512 (motor) jam 14.00 - 15.00.

b. Volume Parkir

Seperti diketahui bahwa volume parkir merupakan jumlah kendaraan yang telah menggunakan ruang parkir pada suatu lahan parkir dalam suatu waktu tertentu. Untuk itu, hasil rekapitulasi volume parkir secara secara keseluruhan dapat dilihat pada Tabel 5.

Tabel 5

Volume Parkir Mobil dan Motor Segmen

1 Pasar Melati Medan

\begin{tabular}{|c|c|c|c|c|c|}
\hline \multirow[t]{2}{*}{ Segmen } & \multirow[t]{2}{*}{ HARI } & \multicolumn{2}{|c|}{ Mobil } & \multicolumn{2}{|c|}{ Motor } \\
\hline & & Kiri & Kanan & Kiri & Kanan \\
\hline \multirow[t]{9}{*}{1} & MINGGU & 109 & 117 & 115 & 84 \\
\hline & SENIN & 87 & 131 & 122 & 122 \\
\hline & SELASA & 152 & 186 & 110 & 118 \\
\hline & RABU & 114 & 155 & 99 & 116 \\
\hline & KAMIS & 77 & 120 & 102 & 124 \\
\hline & JUMAT & 74 & 118 & 109 & 165 \\
\hline & SABTU & 142 & 146 & 105 & 193 \\
\hline & MINGGU & 153 & 210 & 108 & 141 \\
\hline & MAX & 153 & 210 & 122 & 193 \\
\hline
\end{tabular}


Perhitungan volume parkir dilakukan pada kelima segmen. Volume parkir terbesar pada segmen 1 untuk mobil dan motor ialah 210 (mobil) pada hari Minggu, dan 193 (motor) pada hari sabtu. Volume parkir terbesar pada segmen 2 untuk mobil dan motor ialah 166 (mobil) pada hari selasa dan 449 (motor) pada hari jumat. Volume parkir terbesar pada segmen 3 untuk mobil dan motor ialah 84 (mobil) pada hari selasa dan 1237 (motor) pada hari minggu. Volume parkir terbesar pada segmen 4 untuk mobil dan motor ialah 118 (mobil) pada hari rabu dan 683 (motor) pada hari minggu. Volume parkir terbesar pada segmen 5 untuk mobil dan motor ialah 233 (mobil) pada hari minggu dan 1135 (motor) pada hari selasa.

\section{Pemodelan Kebutuhan Parkir}

Untuk memodelkan kebutuhan ruang parkir Pasar Melati Medan akan di pakai beberapa variabel, variabel tidak bebas (dependent variable : Y) dan variabel bebas (independent variable $: \mathrm{X}$ ) yang digunakan pada Tabel berikut:

Tabel 6

Rekapitulasi Hasil Survei untuk Mobil Kiri

\begin{tabular}{lccccccccc}
\hline Segmen & $\begin{array}{c}\text { Akumulasi } \\
\text { Parkir } \\
\text { Mobil }\end{array}$ & $\begin{array}{c}\text { Luas } \\
\text { Pasar }\end{array}$ & $\begin{array}{c}\text { Luas } \\
\text { Kios }\end{array}$ & $\begin{array}{c}\text { Luas } \\
\text { Los }\end{array}$ & $\begin{array}{c}\text { Jumlah } \\
\text { Los }\end{array}$ & $\begin{array}{c}\text { Jumlah } \\
\text { Kios }\end{array}$ & $\begin{array}{c}\text { Jumlah } \\
\text { Pengunjung }\end{array}$ & $\begin{array}{c}\text { Jumlah } \\
\text { Pedagang } \\
\text { Tanah }\end{array}$ & $\begin{array}{c}\text { Volume } \\
\text { Parkir } \\
\text { Mobil }\end{array}$ \\
\hline Y1 & $\mathbf{X 1}$ & $\mathbf{X 2}$ & $\mathbf{X 3}$ & $\mathbf{X 4}$ & $\mathbf{X 5}$ & $\mathbf{X 6}$ & $\mathbf{X 7}$ & $\mathbf{X 8}$ \\
\hline Segmen 1 & 101 & 0 & 0 & 0 & 0 & 0 & 0 & 0 & 153 \\
\hline Segmen 2 & 95 & 7684.5 & 1032 & 3921 & 102 & 16 & 24096 & 143 & 166 \\
\hline Segmen 3 & 61 & 7684.5 & 1506 & 3250 & 96 & 18 & 16427 & 132 & 84 \\
\hline Segmen 5 & 76 & 7684.5 & 4912 & 776 & 20 & 56 & 4841 & 87 & 118 \\
\hline
\end{tabular}

Tabel 7

Rekapitulasi Hasil Survei untuk Mobil Kanan

\begin{tabular}{lccccccccc}
\hline Segmen & $\begin{array}{c}\text { Akumulasi } \\
\text { Parkir } \\
\text { Mobil }\end{array}$ & $\begin{array}{c}\text { Luas } \\
\text { Pasar }\end{array}$ & $\begin{array}{c}\text { Luas } \\
\text { Kios }\end{array}$ & $\begin{array}{c}\text { Luas } \\
\text { Los }\end{array}$ & $\begin{array}{c}\text { Jumlah } \\
\text { Los }\end{array}$ & $\begin{array}{c}\text { Jumlah } \\
\text { Kios }\end{array}$ & $\begin{array}{c}\text { Jumlah } \\
\text { Pengunjung }\end{array}$ & $\begin{array}{c}\text { Jumlah } \\
\text { Pedagang } \\
\text { Tanah }\end{array}$ & $\begin{array}{c}\text { Volume } \\
\text { Parkir } \\
\text { Mobil }\end{array}$ \\
\cline { 2 - 10 } & Y1 & $\mathbf{X 1}$ & $\mathbf{X 2}$ & $\mathbf{X 3}$ & $\mathbf{X 4}$ & $\mathbf{X 5}$ & $\mathbf{X 6}$ & $\mathbf{X 7}$ & $\mathbf{X 8}$ \\
\hline Segmen 1 & 206 & 0 & 0 & 0 & 0 & 0 & 0 & 0 & 210 \\
\hline Segmen 2 & 51 & 7684.5 & 1032 & 3921 & 102 & 16 & 24096 & 143 & 95 \\
\hline Segmen 3 & 9 & 7684.5 & 1506 & 3250 & 96 & 18 & 16427 & 132 & 16 \\
\hline Segmen 4 & 40 & 7684.5 & 4912 & 776 & 20 & 56 & 4841 & 87 & 83 \\
\hline Segmen 5 & 50 & 7684.5 & 2130 & 536 & 13 & 19 & 1627 & 74 & 43 \\
\hline
\end{tabular}

Tabel 8

Rekapitulasi Hasil Survei untuk Motor Kiri

\begin{tabular}{cccccccccc}
\hline Segmen & $\begin{array}{c}\text { Akumulasi } \\
\text { Parkir } \\
\text { Motor }\end{array}$ & $\begin{array}{c}\text { Luas } \\
\text { Pasar }\end{array}$ & $\begin{array}{c}\text { Luas } \\
\text { Kios }\end{array}$ & $\begin{array}{c}\text { Luas } \\
\text { Los }\end{array}$ & $\begin{array}{c}\text { Jumlah } \\
\text { Los }\end{array}$ & $\begin{array}{c}\text { Jumlah } \\
\text { Kios }\end{array}$ & $\begin{array}{c}\text { Jumlah } \\
\text { Pengunjung }\end{array}$ & $\begin{array}{c}\text { Jumlah } \\
\text { Pedagang } \\
\text { Tanah }\end{array}$ & $\begin{array}{c}\text { Volume } \\
\text { Parkir } \\
\text { Motor }\end{array}$ \\
\cline { 2 - 10 } & Y2 & $\mathbf{X 1}$ & $\mathbf{X 2}$ & $\mathbf{X 3}$ & $\mathbf{X 4}$ & $\mathbf{X 5}$ & $\mathbf{X 6}$ & $\mathbf{X 7}$ & $\mathbf{X 8}$ \\
\hline Segmen 1 & 138 & 0 & 0 & 0 & 0 & 0 & 0 & 0 & 122 \\
\hline Segmen 2 & 219 & 7684.5 & 1032 & 3921 & 102 & 16 & 24096 & 143 & 292 \\
\hline Segmen 3 & 853 & 7684.5 & 1506 & 3250 & 96 & 18 & 16427 & 132 & 1020 \\
\hline
\end{tabular}




\begin{tabular}{lccccccccc}
\hline Segmen 4 & 558 & 7684.5 & 4912 & 776 & 20 & 56 & 4841 & 87 & 677 \\
\hline Segmen 5 & 66 & 7684.5 & 2130 & 536 & 13 & 19 & 1627 & 74 & 95 \\
\hline
\end{tabular}

Tabel 9

Rekapitulasi Hasil Survei untuk Motor Kanan

\begin{tabular}{ccccccccccc}
\hline Segmen & $\begin{array}{c}\text { Akumulasi } \\
\text { Parkir } \\
\text { Motor }\end{array}$ & $\begin{array}{c}\text { Luas } \\
\text { Pasar }\end{array}$ & $\begin{array}{c}\text { Luas } \\
\text { Kios }\end{array}$ & $\begin{array}{c}\text { Luas } \\
\text { Los }\end{array}$ & $\begin{array}{c}\text { Jumlah } \\
\text { Los }\end{array}$ & $\begin{array}{c}\text { Jumlah } \\
\text { Kios }\end{array}$ & $\begin{array}{c}\text { Jumlah } \\
\text { Pengunjung }\end{array}$ & $\begin{array}{c}\text { Jumlah } \\
\text { Pedagang } \\
\text { Tanah }\end{array}$ & $\begin{array}{c}\text { Volume } \\
\text { Parkir } \\
\text { Motor }\end{array}$ \\
\cline { 2 - 11 } & Y2 & $\mathbf{X 1}$ & $\mathbf{X 2}$ & $\mathbf{X 3}$ & $\mathbf{X 4}$ & $\mathbf{X 5}$ & $\mathbf{X 6}$ & $\mathbf{X 7}$ & $\mathbf{X 8}$ \\
\hline Segmen 1 & 177 & 0 & 0 & 0 & 0 & 0 & 0 & 0 & 193 \\
\hline Segmen 2 & 395 & 7684.5 & 1032 & 3921 & 102 & 16 & 24096 & 143 & 449 \\
\hline Segmen 3 & 1115 & 7684.5 & 1506 & 3250 & 96 & 18 & 16427 & 132 & 1237 \\
\hline Segmen 4 & 731 & 7684.5 & 4912 & 776 & 20 & 56 & 4841 & 87 & 683 \\
\hline Segmen 5 & 1512 & 7684.5 & 2130 & 536 & 13 & 19 & 1627 & 74 & 1135 \\
\hline
\end{tabular}

a. Hubungan antar Variabel Bebas

Dalam suatu pemodelan harus terdapat korelasi antara variabel terikat dan variabel bebas. Variabel bebas dalam pemodelan ini adalah luas pasar (X1), luas kios (X2), luas los (X3), jumlah los (X4), jumlah kios (X5), jumlah pengunjung (X6), Jumlah Pedagang Tanah (X7) dan Volume Parkir Mobil (X8). Aturan yang digunakan adalah antara variabel terikat dengan variabel bebas harus berkorelasi kuat baik positif atau negative (R2 mendekati 1 atau -1) dan sesama variabel bebas tidak boleh saling berkorelasi (R2 mendekati 0). Antar variabel bebas tidak boleh terdapat hubungan (korelasi). Contoh hubungan antar variabel bebas dapat dilihat pada Tabel.

Tabel 10

Hubungan Antar Variabel Bebas (Mobil-Kiri)

\begin{tabular}{clccccc}
\hline No. & Hubungan & $\mathbf{R}$ & $\mathbf{R}^{\mathbf{2}}$ & Coeficient & Konstanta & Significant \\
\hline 1 & X1 dan X2 & 0,580 & 0,336 & 1,079 & 4079,769 & 0,305 \\
\hline 2 & X1 dan X3 & 0,538 & 0,289 & 1,049 & 4368,644 & 0,350 \\
\hline 3 & X1 dan X4 & 0,529 & 0,280 & 37,305 & 4424,111 & 0,359 \\
\hline 4 & X1 dan X5 & 0,591 & 0,349 & 98,496 & 4000,386 & 0,294 \\
\hline 5 & X1 dan X6 & 0,504 & 0,254 & 0,166 & 4586,968 & 0,387 \\
\hline 6 & X1 dan X7 & 0,858 & 0,737 & 51,950 & 1617,589 & 0,063 \\
\hline 7 & X1 dan X8 & 0,022 & 0,000 & $-1,349$ & 6351,051 & 0,972 \\
\hline 8 & X2 dan X1 & 0,580 & 0,336 & 0,312 & 2,274000 & 0,305 \\
\hline 9 & X2 dan X3 & 0,181 & 0,33 & $-0,190$ & 2237,892 & 0,771 \\
\hline 10 & X2 dan X4 & 0,185 & 0,34 & $-7,022$ & 2240,412 & 0,765 \\
\hline 11 & X2 dan X5 & 0,987 & 0,974 & 88,381 & $-10,701$ & 0,002 \\
\hline 12 & X2 dan X6 & 0,171 & 0,029 & $-0,030$ & 2200,899 & 0,783 \\
\hline 13 & X2 dan X7 & 0,229 & 0,052 & 7,439 & 1267,307 & 0,711 \\
\hline 14 & X2 dan X8 & 0,172 & 0,029 & $-5,661$ & 2769,741 & 0,783 \\
\hline 15 & X3 dan X1 & 0,538 & 0,289 & 0,276 & 0,0000 & 0,350 \\
\hline 16 & X3 dan X2 & 0,181 & 0,33 & $-0,173$ & 2027,917 & 0,771 \\
\hline 17 & X3 dan X4 & 0,996 & 0,991 & 35,991 & 33,834 & 0,00 \\
\hline 18 & X3 dan X5 & 0,069 & 0,005 & $-5,911$ & 1825,459 & 0,912 \\
\hline 19 & X3 dan X6 & 0,990 & 0,979 & 0,167 & 124,052 & 0,001 \\
\hline 20 & X3 dan X7 & 0,892 & 0,795 & 27,690 & $-717,925$ & 0,042 \\
\hline
\end{tabular}


Orlando Ricky Daniel, Ahmad Perwira Mulia, Ridwan Anas

\begin{tabular}{|c|c|c|c|c|c|c|}
\hline 21 & $\mathrm{X} 3$ dan X8 & 0,352 & 0,124 & $-11,084$ & 3368,103 & 0,561 \\
\hline 22 & $\mathrm{X} 4$ dan X1 & 0,529 & 0,280 & 0,08 & 7,105 & 0,359 \\
\hline 23 & $\mathrm{X} 4$ dan X2 & 0,185 & 0,034 & $-0,005$ & 55,585 & 0,765 \\
\hline 24 & $\mathrm{X} 4$ dan X3 & 0,996 & 0,991 & 0,028 & $-0,536$ & 0,000 \\
\hline 25 & $\mathrm{X} 4$ dan X5 & 0,077 & 0,006 & $-0,182$ & 50,158 & 0,902 \\
\hline 26 & $\mathrm{X} 4$ dan X6 & 0,974 & 0,949 & 0,005 & 3,375 & 0,005 \\
\hline 27 & $\mathrm{X} 4$ dan X7 & 0,886 & 0,785 & 0,761 & $-20,165$ & 0,045 \\
\hline 28 & $\mathrm{X} 4$ dan $\mathrm{X} 8$ & 0,407 & 0,166 & $-0,355$ & 99,750 & 0,496 \\
\hline 29 & $\mathrm{X} 5$ dan $\mathrm{X} 1$ & 0,591 & 0,349 & 0,004 & 3,553 & 0,294 \\
\hline 30 & $\mathrm{X} 5$ dan X2 & 0,987 & 0,974 & 0,11 & 0,689 & 0,002 \\
\hline 31 & X5 dan X3 & 0,069 & 0,005 & $-0,001$ & 23,172 & 0,912 \\
\hline 32 & $\mathrm{X} 5$ dan $\mathrm{X} 4$ & 0,077 & 0,006 & $-0,032$ & 23,299 & 0,902 \\
\hline 33 & $\mathrm{X} 5$ dan X6 & 0,048 & 0,002 & $-9,467$ & 22,690 & 0,939 \\
\hline 34 & $\mathrm{X} 5$ dan X7 & 0,307 & 0,094 & 0,111 & 12,084 & 0,616 \\
\hline 35 & $\mathrm{X} 5$ dan $\mathrm{X} 8$ & 0,267 & 0,071 & $-0,098$ & 36,653 & 0,664 \\
\hline 36 & $\mathrm{X} 6$ dan X1 & 0,504 & 0,254 & 1,529 & 1,819 & 0,387 \\
\hline 37 & $\mathrm{X} 6$ dan X2 & 0,171 & 0,029 & $-0,966$ & 11249,834 & 0,783 \\
\hline 38 & $\mathrm{X} 6$ dan X3 & 0,990 & 0,979 & 5,853 & $-531,452$ & 0,001 \\
\hline 39 & $\mathrm{X} 6$ dan X4 & 0,974 & 0,949 & 208,239 & $-222,451$ & 0,005 \\
\hline 40 & X6 dan X5 & 0,048 & 0,002 & $-24,208$ & 9925,932 & 0,939 \\
\hline 41 & $\mathrm{X} 6$ dan X7 & 0,869 & 0,755 & 159,553 & $-4514,919$ & 0,056 \\
\hline 42 & $\mathrm{X} 6$ dan X8 & 0,324 & 0,105 & $-60,340$ & 18497,488 & 0,595 \\
\hline 43 & $\mathrm{X} 7$ dan X1 & 0,858 & 0,737 & 0,014 & $-2,8420$ & 0,063 \\
\hline 44 & $\mathrm{X} 7$ dan X2 & 0,229 & 0,052 & 0,007 & 73,724 & 0,711 \\
\hline 45 & X7 dan X3 & 0,892 & 0,795 & 0,029 & 38,466 & 0,042 \\
\hline 46 & $\mathrm{X} 7$ dan $\mathrm{X} 4$ & 0,886 & 0,785 & 1,032 & 39,544 & 0,045 \\
\hline 47 & $\mathrm{X} 7$ dan X5 & 0,307 & 0,094 & 0,845 & 68,779 & 0,616 \\
\hline 48 & $\mathrm{X} 7$ dan X6 & 0,869 & 0,755 & 0,005 & 42,727 & 0,056 \\
\hline 49 & $\mathrm{X} 7$ dan $\mathrm{X} 8$ & 0,269 & 0,072 & $-0,273$ & 128,295 & 0,662 \\
\hline 50 & $\mathrm{X} 8$ dan $\mathrm{X} 1$ & 0,022 & 0,000 & 0,000 & 153,000 & 0,972 \\
\hline 51 & $\mathrm{X} 8$ dan $\mathrm{X} 2$ & 0,172 & 0,029 & $-0,005$ & 160,763 & 0,783 \\
\hline 52 & $\mathrm{X} 8$ dan $\mathrm{X} 3$ & 0,352 & 0,124 & $-0,011$ & 169,752 & 0,561 \\
\hline 53 & $\mathrm{X} 8$ dan $\mathrm{X} 4$ & 0,407 & 0,166 & $-0,468$ & 172,402 & 0,496 \\
\hline 54 & $\mathrm{X} 8$ dan X5 & 0,267 & 0,071 & $-0,726$ & 166,619 & 0,664 \\
\hline 55 & $\mathrm{X} 8$ dan X6 & 0,324 & 0,105 & $-0,002$ & 167,139 & 0,595 \\
\hline 56 & $\mathrm{X} 8$ dan X7 & 0,269 & 0,072 & $-0,265$ & 173,885 & 0,662 \\
\hline
\end{tabular}

b. Hubungan Korelasi antar Variabel

Masing-masing variabel diuji korelasinya untuk mengetahui mana variabel yang dapat digunakan dan yang tidak bisa digunakan. Uji korelasi dengan bantuan program SPSS didapatkan hasil korelasi antar variabel.

Tabel 11

Hubungan Korelasi Antar Variabel Mobil (Kiri)

\begin{tabular}{ccccccc}
\hline No. & Hubungan & $\mathbf{R}$ & $\mathbf{R}^{\mathbf{2}}$ & Coeficient & Konstanta & Significant \\
\hline 1 & Ymobil dan X1 & 0,112 & 0,013 & 0,002 & 101,00 & 0,858 \\
\hline 2 & Ymobil dan X2 & 0,040 & 0,002 & $-0,002$ & 119,083 & 0,950 \\
\hline 3 & Ymobil dan X3 & 0,420 & 0,176 & $-0,018$ & 146,280 & 0,481 \\
\hline 4 & Ymobil dan X4 & 0,446 & 0,199 & $-0,685$ & 147,647 & 0,452 \\
\hline 5 & Ymobil dan X5 & 0,174 & 0,030 & $-0,633$ & 129,804 & 0,779 \\
\hline
\end{tabular}




\begin{tabular}{ccccccc}
\hline 6 & Ymobil dan X6 & 0,445 & 0,198 & $-0,003$ & 146,037 & 0,453 \\
\hline 7 & Ymobil dan X7 & 0,238 & 0,057 & $-0,314$ & 143,373 & 0,700 \\
\hline 8 & Ymobil dan X8 & 0,918 & 0,843 & 1,229 & $-69,353$ & 0,028 \\
\hline
\end{tabular}

Dari hasil korelasi antara variabel terikat dan varibel bebas dari regresi sederhana diatas, dilakukan kembali pengujian terhadap $\mathrm{R}^{2}$ terbesar untuk regresi linier berganda yaitu Ymobil dan X4 dan Ymobil dan X8. Selanjutnya variabel terikat dimodelkan dengan variabel bebasnya dengan hasil sebagai berikut:

\begin{tabular}{|c|c|c|c|c|}
\hline \multicolumn{5}{|c|}{ Model Summary } \\
\hline Model & $\mathbf{R}$ & $\begin{array}{c}\mathbf{R} \\
\text { Square }\end{array}$ & $\begin{array}{c}\text { Adjusted R } \\
\text { Square }\end{array}$ & $\begin{array}{l}\text { Std. Error } \\
\text { of the } \\
\text { Estimate }\end{array}$ \\
\hline 1 & $.922^{\mathrm{a}}$ & .849 & .699 & 41.12243 \\
\hline
\end{tabular}

\begin{tabular}{|c|c|c|c|c|c|}
\hline \multicolumn{6}{|c|}{ Coefficients $^{\mathrm{a}}$} \\
\hline \multirow[t]{2}{*}{ Model } & \multicolumn{2}{|c|}{$\begin{array}{l}\text { Unstandardized } \\
\text { Coefficients }\end{array}$} & $\begin{array}{c}\text { Standardiz } \\
\text { ed }\end{array}$ & $\mathbf{t}$ & Sig. \\
\hline & B & Std. Error & Beta & & \\
\hline 1 (Constant) & -56.161 & 74.345 & & -.755 & .529 \\
\hline JUMLAHLOS & -.132 & .462 & -.086 & -.287 & .801 \\
\hline VPM & 1.182 & .402 & .883 & 2.939 & .099 \\
\hline
\end{tabular}

Dari hasil analisis di atas variabel jumlah los dan volume parkir mobil yang dapat digunakan, karena jumlah los dan volume parkir mobil memiliki korelasi yang tinggi terhadap tarikan kendaraan pada mobil sebelah kiri yang menuju pasar melati medan. Sehingga model yang dihasilkan parkir mobil kiri ialah:

$Y_{\text {mobil }}=-56,161-0,132 \mathrm{X}_{4}+1,182 \mathrm{X}_{8}$

Selain mobil sebelah kiri, parkir mobil sebelah kanan juga menjadi pertimbangan dalam permodelan ini. Dari hasil analisis di atas hanya variabel luas pasar dan volume parkir mobil yang dapat digunakan, karena luas pasar dan volume parkir mobil memiliki korelasi yang tinggi terhadap tarikan kendaraan pada mobil kanan yang menuju pasar melati medan. Sehingga model yang dihasilkan parkir mobil kanan ialah:

$\mathrm{Y}_{\text {mobil }}=123,014-0,014 \mathrm{X}_{1}+0,395 \mathrm{X}_{8}$

Selain mobil sebelah kanan, parkir motor sebelah kiri juga menjadi pertimbangan dalam permodelan ini. Dari hasil korelasi antara variabel terikat dan varibel bebas dari regresi sederhana, dilakukan kembali pengujian terhadap $R^{2}$ terbesar untuk regresi linier berganda yaitu Ymotor dan X7 dan Ymotor dan X8. Selanjutnya variabel terikat dimodelkan dengan variabel bebasnya. dengan hasil sebagai berikut: 


\begin{tabular}{|c|c|c|c|c|}
\hline \multicolumn{5}{|c|}{ Model Summary } \\
\hline Model & $\mathbf{R}$ & $\begin{array}{c}\mathbf{R} \\
\text { Square }\end{array}$ & $\begin{array}{c}\text { Adjusted R } \\
\text { Square }\end{array}$ & $\begin{array}{l}\text { Std. Error } \\
\text { of the } \\
\text { Estimate }\end{array}$ \\
\hline 1 & $1.000^{\mathrm{a}}$ & .999 & .998 & 13.32385 \\
\hline a. Prec & (Const & VPM, JI & & \\
\hline
\end{tabular}

\begin{tabular}{|c|c|c|c|c|c|c|}
\hline \multicolumn{7}{|c|}{ Coefficients $^{\mathbf{a}}$} \\
\hline \multirow{2}{*}{\multicolumn{2}{|c|}{ Model }} & \multicolumn{2}{|c|}{$\begin{array}{l}\text { Unstandardized } \\
\text { Coefficients }\end{array}$} & \multirow{2}{*}{$\begin{array}{c}\text { Standardiz } \\
\text { ed } \\
\text { Coefficients }\end{array}$} & \multirow[t]{2}{*}{$\mathbf{t}$} & \multirow[t]{2}{*}{ Sig. } \\
\hline & & B & Std. Error & & & \\
\hline & (Constant) & 24.542 & 12.019 & & 2.042 & .178 \\
\hline & JPT & -.443 & .141 & -.076 & -3.147 & .088 \\
\hline & VPM & .863 & .020 & 1.040 & 43.031 & .001 \\
\hline
\end{tabular}

Dari hasil analisis di atas hanya variabel jumlah pedagang tanah dan volume parkir motor yang dapat digunakan, karena jumlah pedagang tanah dan volume parkir motor memiliki korelasi yang tinggi terhadap tarikan kendaraan pada motor kiri yang menuju pasar melati medan. Sehingga model yang dihasilkan parkir motor kiri ialah:

$$
Y_{\text {motor }}=24,542-0,443 X_{7}+0,863 X_{8}
$$

Selain motor sebelah kiri, parkir motor sebelah kanan juga menjadi pertimbangan dalam permodelan ini. Dari hasil analisis di atas hanya variabel luas pasar dan volume parkir motor yang dapat digunakan, karena luas pasar dan volume parkir motor memiliki korelasi yang tinggi terhadap tarikan kendaraan pada motor kanan yang menuju pasar melati medan. Sehingga model yang dihasilkan parkir motor kanan ialah:

$$
\mathrm{Y}_{\text {motor }}=-47,194-0,004 \mathrm{X}_{1}+1,162 \mathrm{X}_{8}
$$

c. Validasi Model

Dalam penelitian ini uji validitas digunakan untuk mengukur tingkat interkorelasi antar variabel. Uji validitas dengan bantuan program SPSS.

d. Kebutuhan Ruang Parkir

Berdasarkan persamaan tarikan yang didapat dari analisis sebelumnya, maka didapat kebutuhan parkir adalah:

Tabel 12

Kebutuhan Parkir Pasar Melati Medan

\begin{tabular}{cccccc}
\hline \multicolumn{2}{c}{ Mobil } & \multicolumn{3}{c}{ Motor } \\
\hline Segmen I & 18 & 25 & Segmen I & 17 & 26 \\
\hline Segmen II & 11 & 7 & Segmen II & 27 & 44 \\
\hline Segmen III & 8 & 2 & Segmen III & 92 & 171 \\
\hline Segmen IV & 10 & 11 & Segmen IV & 54 & 82 \\
\hline Segmen V & 29 & 5 & Segmen V & 9 & 156 \\
\hline Total & \multicolumn{2}{c}{126} & Total & \multicolumn{2}{c}{678} \\
\hline
\end{tabular}


SRP Mobil $=2,30 \mathrm{~m} \times 5,00 \mathrm{~m}$

SRP Motor $=0,750 \mathrm{~m} \times 2,00 \mathrm{~m}$

Maka, kebutuhan ruang parkir pasar melati :

KRP Mobil $=($ Akumulasi Maksimum $) \times($ SRP $)$

$$
\begin{aligned}
& =(126) \times(2,30 \mathrm{~m} \times 5,00 \mathrm{~m}) \\
& =1.449 \mathrm{~m}^{2}
\end{aligned}
$$

KRP Motor $=($ Akumulasi Maksimum $) \times($ SRP $)$

$$
=(678) \times(0,750 \mathrm{~m} \times 2,00 \mathrm{~m})
$$$$
=1.017 \mathrm{~m}^{2}
$$

KRP $\square \quad=$ KRP Mobil + KRP Motor

$=1.449 \mathrm{~m}^{2}+1.017 \mathrm{~m}^{2}$

$=2.466 \mathrm{~m}^{2}$

\section{Kesimpulan}

Berdasarkan analisis yang terlah dilakukan maka dapat disimpulkan model tarikan mobil kiri: $\mathrm{Y}=-56,161-0,132 \mathrm{X}_{4}+1,182 \mathrm{X} 8$, model tarikan mobil kanan: $\mathrm{Y}=$ $123,014-0,014 \mathrm{X}_{1}+0,395 \mathrm{X}_{8}$, model tarikan motor kiri: $\mathrm{Y}=24,542-0,443 \mathrm{X}_{7}+$ 0,863 $\mathrm{X}_{8}$, model tarikan motor kanan: $\mathrm{Y}=-47,194-0,004 \mathrm{X}_{1}+1,162 \mathrm{X}_{8}$, Kebutuhan luas area parkir untuk Pasar Melati Medan adalah $2.466 \mathrm{~m}^{2}$. Dari hasil penelitian terdahulu, variabel yang menentukan model kebutuhan ruang parkir ada yang jumlah los, jumlah kios, volume parkir, dan luas pasar. Namun variabel penelitian yang sama dengan tesis ini ialah variabel luas pasar, jumlah los, volume parkir mobil, dan volume parkir motor. 


\section{BIBLIOGRAFI}

Alvesa, A. C. R., Diasa, S. M., Queiroza, K. I. P. de M., de Carvalhob, M. J. M., \& Duarteb, J. M. L. (2019). CONASAT-0: Visão Geral do Nanossatélite Desenvolvido. II Congresso Aeroespacial Brasileiro. Google Scholar

Ansusanto, J. D. dan L. S. (2019). Permodelan Parkir Pada Gedung Perbankan di Kota Yogyakarta. Konferensi Nasional Teknik Sipil 13. Banda Aceh. Google Scholar

Atmaja, K. S. K., Putra, D. A. A., Wicaksono, Y. I., \& Indriastuti, A. K. (2013). Perencanaan Ulang Desain Parkir Pasar Bulu Kota Semarang. Jurnal Karya Teknik Sipil, 2(3), 141-150. Google Scholar

Lestari, U. . dan N. (2018). Evaluasi Karakteristik dan Kapasitas Lahan Parkir Pada Rumah Sakit Daerah Idaman Banjarbaru. Jurnal Intekna, 18(2). Google Scholar

Miro, F. (2005). Perencanaan Transportasi untuk Mahasiswa. Perencana dan Praktisi, Penerbit Erlangga, Jakarta. Google Scholar

Putu Fany, Y., I Ketut, A., \& I Nyoman Gede, S. (2014). Efektivitas penggunaan media cetak dan media elektronika dalam promosi kesehatan terhadap peningkatan pengetahuan dan perubahan sikap siswa SD. Google Scholar

Saragih, Y. S. (2016). Image Pembeli Pakaian Bekas Di Pasar Melati Kecamatan Medan Tuntungan, Provinsi Sumatera Utara. Unimed. Google Scholar

Sudirahardjo, R. (2003). Analisis Kebutuhan Ruang Parkir Di Pasar Bandarjo Ungaran. Magister Teknik Sipil. Google Scholar

Tamin, O. . (1997). Perencanaan dan Pemodelan Transportasi. Teknik Sipil Institut Teknologi Bandung. Google Scholar

Wahida, N., Anggraini, R., \& Isya, M. (2018). Perencanaan kebutuhan ruang parkir di kawasan taman Sari kota banda aceh. Jurnal Arsip Rekayasa Sipil Dan Perencanaan, 1(4), 11-21. Google Scholar

Warpani, S. (1990). Merencanakan Sistem Perangkutan. Bandung: Penerbit ITB. Google Scholar 
Zaenal, R. F. et al. (2019). Analysis of Characteristic and Parking Demand (A Case Study: New Makassar Mall). American Journal of Engineering Research (AJER), 8(11), 130-135. Google Scholar

\section{Copyright holder:}

Orlando Ricky Daniel, Ahmad Perwira Mulia, Ridwan Anas (2022)

First publication right:

Jurnal Syntax Admiration

This article is licensed under:

(c) $\underset{\mathrm{EY}}{\mathrm{C}} \mathrm{SA}$ 